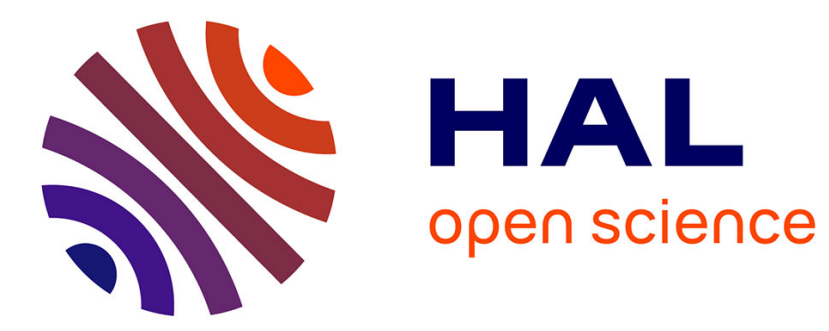

\title{
COBALT SEGREGATION IN CARBIDE GRAIN BOUNDARIES IN WC-Co COMPOSITES
}

\author{
J. Vicens, A. Dubon, J. Laval, M. Benjdir, G. Nouet
}

\section{To cite this version:}

J. Vicens, A. Dubon, J. Laval, M. Benjdir, G. Nouet. COBALT SEGREGATION IN CARBIDE GRAIN BOUNDARIES IN WC-Co COMPOSITES. Journal de Physique Colloques, 1990, 51 (C1), pp.C1-347-C1-352. 10.1051/jphyscol:1990155 . jpa-00230316

\section{HAL Id: jpa-00230316 https://hal.science/jpa-00230316}

Submitted on 1 Jan 1990

HAL is a multi-disciplinary open access archive for the deposit and dissemination of scientific research documents, whether they are published or not. The documents may come from teaching and research institutions in France or abroad, or from public or private research centers.
L'archive ouverte pluridisciplinaire HAL, est destinée au dépôt et à la diffusion de documents scientifiques de niveau recherche, publiés ou non, émanant des établissements d'enseignement et de recherche français ou étrangers, des laboratoires publics ou privés. 
COLLOQUE DE PHYSIQUE

Colloque C1, supplément au $\mathrm{n}^{\circ} 1$, Tome 51, janvier 1990

COBALT SEGREGATION IN CARBIDE GRAIN BOUNDARIES IN WC-Co COMPOSITES

J. VICENS, A. DUBON*, J.Y. LAVAL*, M. BENJDIR and G. NOUET

Laboratoire d'Etudes et de Recherches sur les Matériaux, CNRS URA 1317 , Institut des Sciences de la Matière et du Rayonnement, Boulevard du Maréchal Juin, F-14032 Caen Cedex, France

*Laboratoire des Microstructures, CNRS-ESPCI, 10 Rue Vauquelin, F-75231 Paris Cedex 05, France

Résumé - La concentration en cobalt aux joints de grains carbure-carbure des composites WC-Co a été déterminée par microanalyse $x$ à sélection d'énergie en microscopie électronique à balayage en transmission. Des profils de concentration en cobalt ont été obtenus dans des joints de grains $\Sigma 2$ et $\Sigma 5$ ayant tous un plan de joint parallèle au plan prismatique $\{10 \overline{1} 0\}$. Dans le cas des joints de grains $\Sigma 2$ et $\Sigma 5$ il a été montré qu'une faible ségrégation en cobalt est détectée lorsque des dislocations ont pu être observées dans l'interface. La valeur de cette ségrégation est comparée à celle obtenue dans des joints de faible désorientation et dans des joints généraux.

Abstract - The cobalt concentration at wC-WC grain boundaries in WC-Co composites was determined via X-ray energy dispersive analysis in STEM. Cobalt profiles were performed across coincidence grain boundaries $\Sigma 2$ and $\Sigma 5$ with a $\{10 \overline{1} 0\}$ prismatic plane. A small cobalt segregation has been detected when dislocations were imaged in the grain boundaries. The cobalt segregation value is compared to the segregation ratio obtained in low angle and general grain boundaries.

\section{1 - INTRODUCTION}

Cermets, a special class of carbide ceramics, are materials of interest because of their high thermomechanical properties, mainly due to their composition which is a mixture of brittle (hard) and ductile (soft) phases. A typical cermet is the composite material: tungsten carbide-cobalt (WC-CO). This material is prepared by a liquid phase sintering process with the cobalt phase acting as the binder phase. In the case of tungsten carbide and cobalt alloys the very low interfacial energy between the two phases results in a nearly perfect wetting and consequently in a very good adhesion in the solid state $/ 1,2 /$. During the sintering process at $1400^{\circ} \mathrm{C}$ the liquid cobalt phase can dissolve tungsten carbide crystals to some extent. After saturation of the Iiquid cobalt phase and during the cooling of the specimens, precipitation, redeposition and growth of tungsten carbide crystals on preexisting carbide crystals occur giving rise to the well characterized microstructure of such specimens. As for any polycrystalline material, interfaces and especially carbide-carbide grain boundaries play an important role in determining properties. Thus for a good knowledge of the properties of these materials a precise description of the intergranular structure is required. 
Much discussion has taken place concerning the continuity of the wC crystals (hexagonal $a=.2906 \mathrm{~nm}, c=.2837 \mathrm{~nm}$ ) and the existence of a continuous cobalt film in the carbide grain boundaries. Several TEM techniques have been used such as lattice imaging of both grains at the interface $/ 3 /$, structure imaging in HREM $/ 4 /$, STEM-EDX analysis $/ 5,6 /$, Fresnel fringe imaging $/ 7 /$. Other special analysis techniques have also been used such as Auger spectroscopy $/ 8,9 /$ and field ion microscopy /10,11/. Lattice imaging /3/ and HREM studies /4/ have confirmed the continuity of the WC grains which appear to be free from cobalt. Cobalt segregation has been found in grain boundaries /5/ and mainly in general grain boundaries /6/. Field ion microscopy and TEM /10,11/ have shown the presence of cobalt in the form of half an atomic monolayer in grain boundaries. In a few studies $. / 4,11 /$ cobalt analyses have been performed on grain boundaries where crystallographic descriptions have been previously determined. Precise descriptions based on the coincidence theory can be given for the hexagonal carbide crystals (with $c / a=1$ ) $/ 12 /$. The aim of this work is to refine the correlation between geometric description based on the coincidence site theory and cobalt segregation at grain boundaries in WC-Co alloys where a high number of coincidence grain boundaries has been observed /4/. The usual grain boundary plane found between carbide grains in WC-Co cermets is the $\{10 \overline{0} 0\}$ prismatic plane. Thus we consider here different types of low energy twist boundaries admitting the prismatic plane as boundary plane.

\section{2 - EXPERIMENTAL METHODS}

WC-Co cemented carbide alloys containing 20 wt\% Co have been prepared by liquid phase (cobalt) sintering at $1400^{\circ} \mathrm{C}$. The wC grain size is $1 \mu \mathrm{m}$. Thin foils have been prepared by ion milling ( $\mathrm{Ar}^{+}, 6 \mathrm{KV}$ ) for TEM studies (Jeol $100 \mathrm{KV}$ ). The cobalt concentration has been determined via $\mathrm{X}$-ray energy dispersive analyses in STEM by selecting $W\left(L_{\alpha}-8.425 \mathrm{KeV}\right)$ peak and the nearby $\mathrm{Co}\left(\mathrm{K}_{\alpha}-7.065 \mathrm{KeV}\right)$ peak. The analyses have been performed in the spot mode in a direction perpendicular to the grain boundary which is orientated parallel to the electron beam. Cobalt segregation profiles have been carried out on several types of carbide grain boundaries previously orientated in TEM. The Co/W (wt\%) ratios are given with respect to the distance d $(\mathrm{nm})$.

\section{3 - CRYSTALLOGRAPHIC DATA}

Due to the sintering process, different grain boundaries can be found in the WC-Co composites. We present in this work five cobalt profiles (among twenty analysed) obtained across the grain boundaries listed in table I with their crystallographic data. The deviation from the exact coincidence orientation has been indicated in table $I$.

\section{4 - SPATIAL RESOLUTION}

Two parameters concerning the $X$-ray energy dispersive analysis (spatial resolution and its variation with the thickness of the analysed area) have been experimentaly determined. The spatial resolution value depends on the probe diameter and the broadening of the beam due 
to multiple scattering in the sample. Several cobalt profiles taken at a cobalt-carbide interface have given a mean spatial resolution value equal to $\sim 45 \mathrm{~nm}$ in diameter. The same experiment performed for different thickness $t$ of the sample have shown a broadening of the spatial resolution equal to $20 \%(t>50 \mathrm{~nm})$ and $40 \%(t>200 \mathrm{~nm})$.

\begin{tabular}{|c|c|c|c|c|c|}
\hline$\#$ & $\Sigma$ & $\begin{array}{c}\text { Rotation } \\
\text { axis }\end{array}$ & $\begin{array}{c}\text { Rotation } \\
\text { angle }\end{array}$ & Deviation & $\begin{array}{c}\text { Grain boundary } \\
\text { plane }\end{array}$ \\
\hline 1 & 1 & {$[11 \overline{2} 0]$} & $3^{\circ}$ & & $(10 \overline{1} 0)_{1,2}$ \\
2 & 2 & {$[10 \overline{1} 0]$} & $90^{\circ}$ & $1^{\circ} 7$ & $" 1$ \\
3 & 5 & {$[10 \overline{1} 0]$} & $53^{\circ} 13$ & $7^{\circ}$ & $" 1$ \\
4 & 2 & {$[10 \overline{1} 0]$} & $90^{\circ}$ & $6^{\circ}$ & $" 1$ \\
5 & 5 & {$[10 \overline{1} 0]$} & $53^{\circ} 13$ & $1^{\circ} 8$ & $"$ \\
\hline
\end{tabular}

Table I : Crystallographic data corresponding to the boundaries displayed in Fig. I to 5 .

\section{5 - COBALT CONCENTRATION PROFILES}

The mean $C o / W$ (wt\%) ratio found in the WC crystals corresponds to a solubility of Co in WC equal to $1 \mathrm{wt} \%$. A variation of this ratio has been observed. It is likely to be due to artefacts (topography of the analysed area for instance) which enhance the cobalt peak intensity.

Among the five boundaries (G.B) listed in table I three G.Bs (Fig. 1 to 3) reveal a cobalt segregation at the grain boundary plane. The first G.B (\# 1) is a low angle grain boundary between two adjacent carbide grains (Fig. 1a). In the orientation shown the grain boundary plane (1010) is parallel to the electron beam. The two crystals are slightly misorientated $\left(\Delta \theta=3^{\circ}\right)$ around the [1120] common axis. A regular array of dislocations is imaged in the grain boundary plane with a mean separation distance equal to $9 \mathrm{~nm}$. It consists of a wall of $a / 3<11 \overline{2} 0>$ mixed dislocations. Only a part of the Burgers vector gives rise to the tilt rotation. A detailed analysis of this configuration is given elsewhere /13/. The cobalt segregation ratio found is equal to $\sim 2$ (Fig. 1b). This result emphasizes the role of the dislocation configuration with respect to the cobalt segregation. It is well known that solute atoms segregate to dislocation cores /14, $15 /$.

Coincidence orientations $\Sigma 2$ and $\Sigma 5$ described by a rotation around the $\langle 10 \overline{1} 0\rangle$ axis have often been found. Such G.BS have been studied in four cases (\# 2 to 5 table I). The boundary planes are shown parallel to the electron beam in Fig. 2 a to $5 \mathrm{a}$. Cobalt profiles are given in Fig. $2 \mathrm{~b}$ to $5 \mathrm{~b}$. The two first profiles (Fig. $2 \mathrm{~b}$ and $3 \mathrm{~b}$ ) reveal a cobalt segregation with a segregation ratio equal to 2.1 $(\Sigma 2)$ and $1.4(\Sigma 5)$. This segregation ratio is smaller than the cobalt segregation $(>3)$ found in G.Bs with a more general crystallographic descriptions $/ 6,16 /$. No noticeable cobalt segregation was observed for G.Bs \# 4 and 5 . 
Dislocations have been imaged in the two G.Bs ( $\Sigma 2$ and $\Sigma 5$ ) which exhibit cobalt segregation (\# 2 and 3 ). High number of dislocations (extrinsic) have interacted with the $\Sigma 2$ G.B (Fig. 2a). A well defined array of dislocations is imaged edge on in the $\Sigma 5$ G.B (Fig. 3a). Conversely, other $\Sigma 2$ and $\Sigma 5$ boundaries (\# 4 and 5) have a very low density of dislocations in or near the interface (see Fig. $4 a$ and 5a) and these show no evidence of segregation. Thus it appears that extrinsic dislocations play a main role for the segregation and therefore it is not possible to establish a direct correlation between the deviation from exact coincidence and the intergranular segregation.

\section{6 - CONCLUSION}

Cobalt concentration has been measured across a number of low energy twist boundaries (coincidence) or low angle GB's previously characterized by electron diffraction admitting the prismatic plane as boundary plane. It is shown that segregation occurs only at those boundaries containing extrinsic dislocation networks. This is consistent with the observation that segregations are also observed at low angle tilt boundaries.

\section{REFERENCES}

/1/ EXNER, H.E., International Metals Reviews, 4, 1979, 149.

/2/ EXNER, H.E. and FISCHMEISTER, H., Z. MetalKd, 57, 1966, 187.

/3/ JAYARAN, V. and SINCLAIR, R., J. Am. Ceram. Soc., 66, 1983, C 137.

/4/ VICENS, J., LAURENT-PINSON, E., CHERMANT, J.L. and NOUET, G., J. Phys. C5, 10, 1988, 171.

/5/ SHARMA, N.K., WARD, I.D., FRASER, H.L. and WILLIAMS, W.S., J. Am. Ceram. Soc. , 63, 1980, 194 .

16/ IAAVAL, J.Y., VICENS, J. and NOUET, G., J. Phys. C2, 145, 1984, 695.

/7/ NESS, J.N., STOBBS, W.N. and PAGE, T.F., Phil. Mag. A, 54, 1986,679 .

/8/ VISWANADAM, R.K., SUN, T.S., DRAKE, E.F. and PECK, J.A., J. Mat. Sci., 16, 1981, 1029 .

19/ LEA, C. and ROEBUCK, B., Met. Sci., 15, 1981, 262.

/10/ HENJERED, A., HELLSING, M. , ANDREN, H.O. and NORDEN, H., "Science of hard materials" ALMOND, E.A., BROOKES, C.A.' WARREN, R., Eds. Inst. Physics Conf. Ser'. 75, Bristol 1986, 313.

111/ HENJERED, A., HELLSING, M., ANDREN, H.O. and NORDEN, H., Mat. Sci. Tech., $\underline{2}, 1986,847$.

/12/ BLERIS, G.L., NOUET, G., HAGEGE, S. and DELAVIGNETTE, P., Acta cryst., A38, 1982,550 .

113/ VICENS, J., BENJDIR, M., DUBON, A., LAVAL, J.Y. and NOUET, G., 12 ICXOM, CRACOW, 1989, to be published.

114/ MICHAEL, J.R., LIN, C.H. and SASS, S.L., Scripta. Met., 22, 1988,1181 .

/15/ GREENBERG, A., KOMEN, Y. and BAUER, C.L., Scripta. Met., 17, 1983,405 .

116/ VICENS, J., DUBON, A., LAVAL, J.Y. and NOUET, G., 11 ICXOM LONDON, (CANADA) Edited by BROWN, J.D. and PACKWOOD, R.H., ONTARIO, CANADA, 1987, 356. 

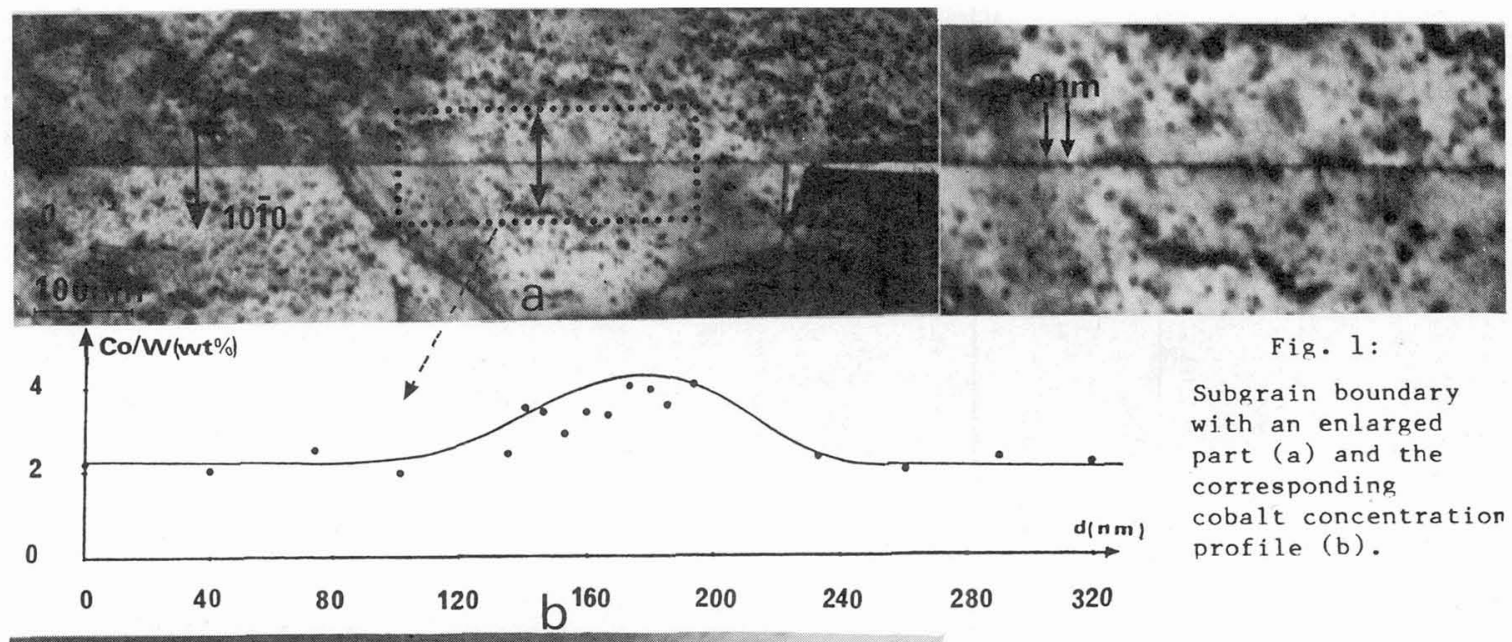

Fig. 1:

Subgrain boundary with an enlarged part (a) and the corresponding cobalt concentration profile (b).

Fig. 2 : $\Sigma 2$

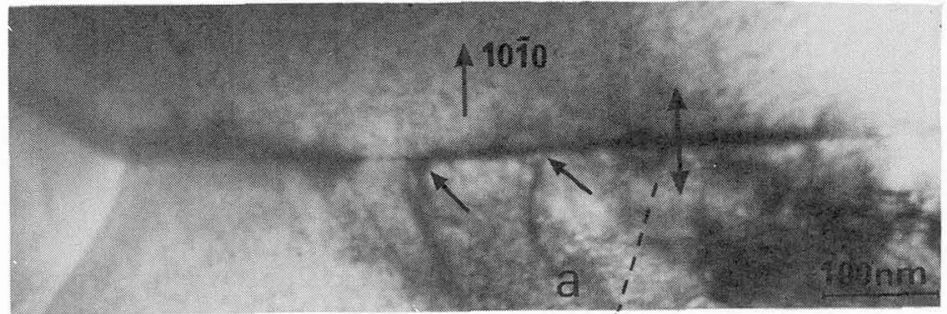

Several dislocations (arrowed)

interact with the G.B. (a).

Cobalt concentration profile (b).
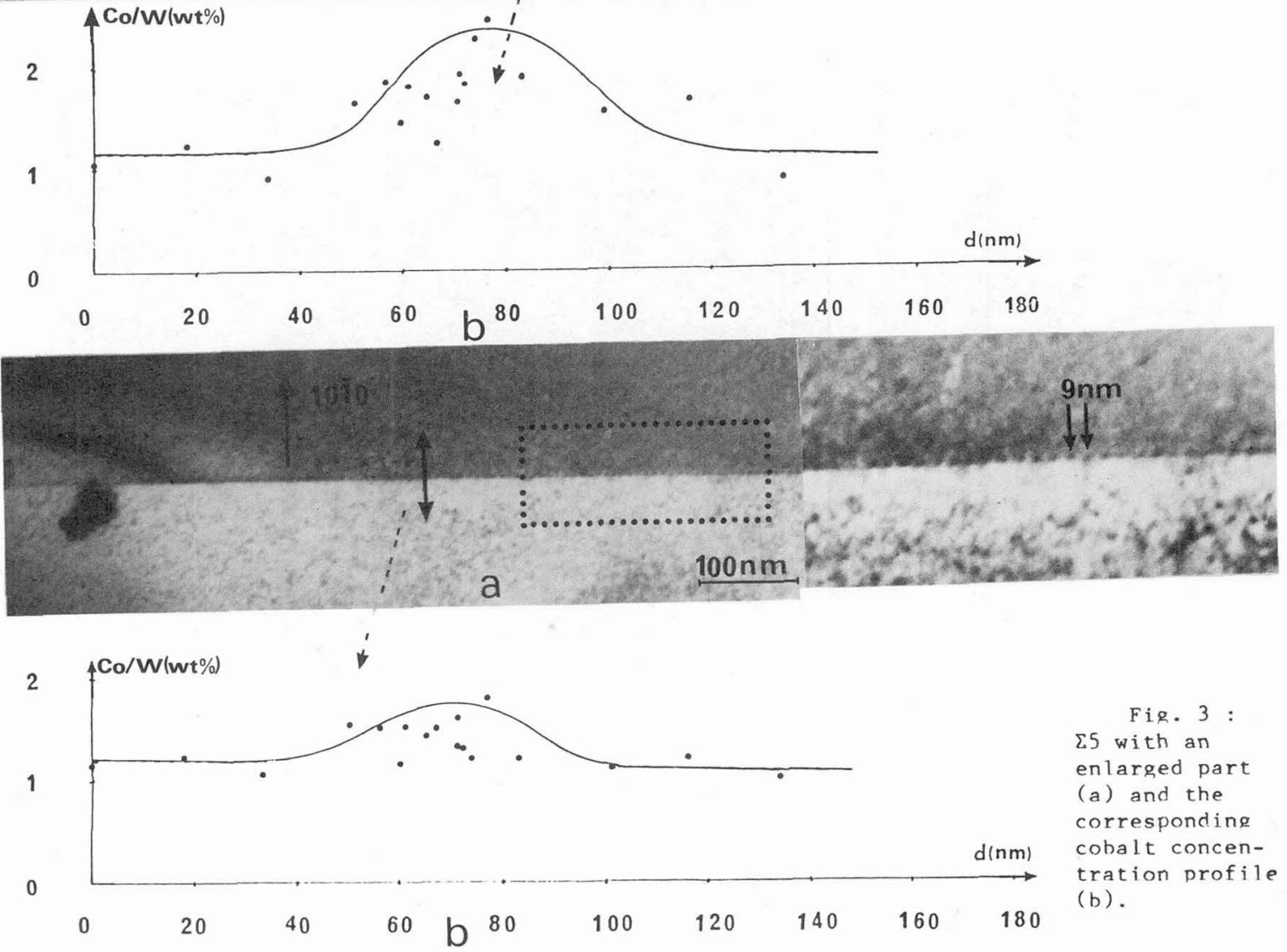

Fig. 3 :

$\sum 5$ with an enlarged part (a) and the corresponding cobalt concentration profile (b). 


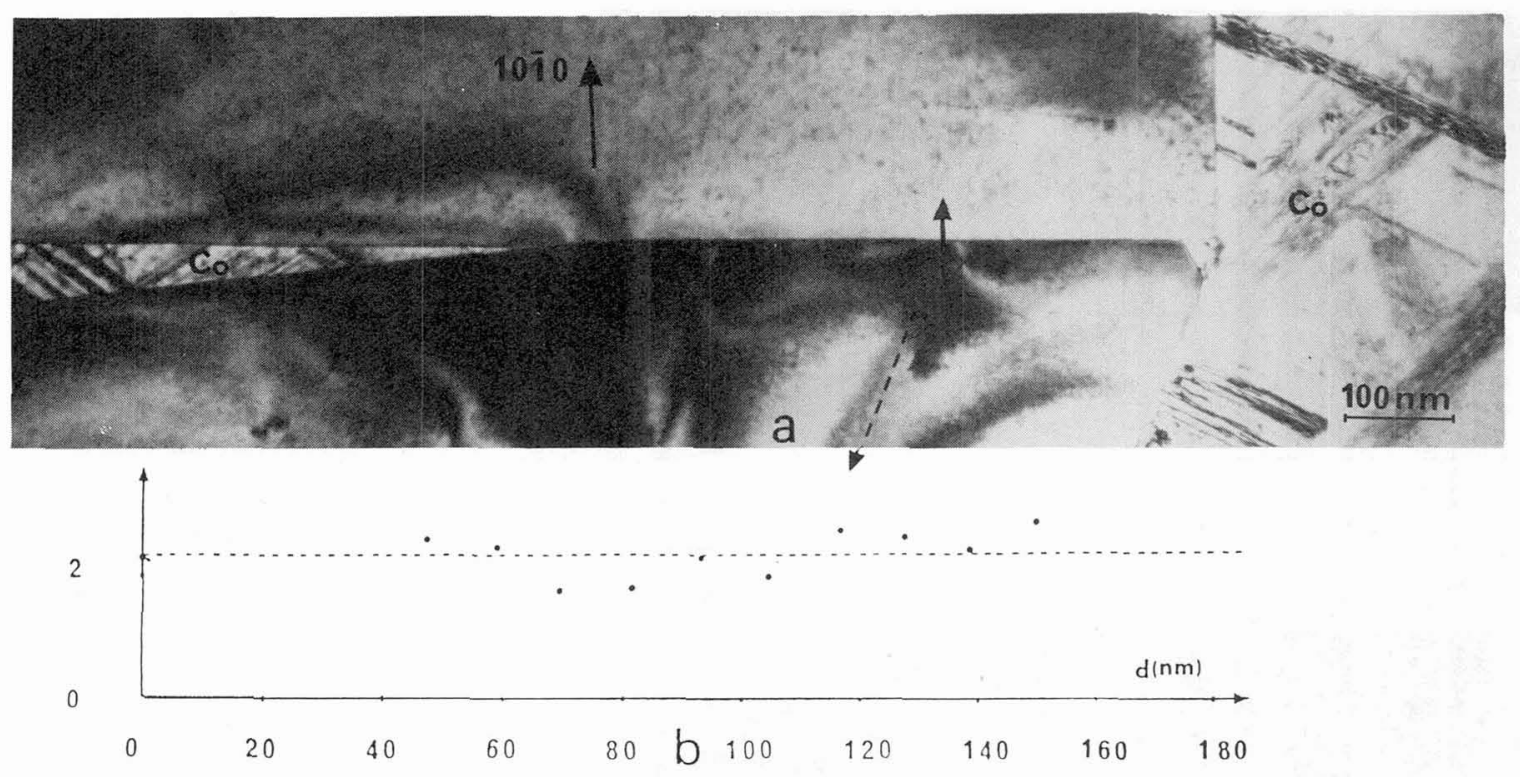

Fig. 4 : Perfect dewetting observed in a $\Sigma 2$ (a) with its correspondine cobalt concentration profile (b).
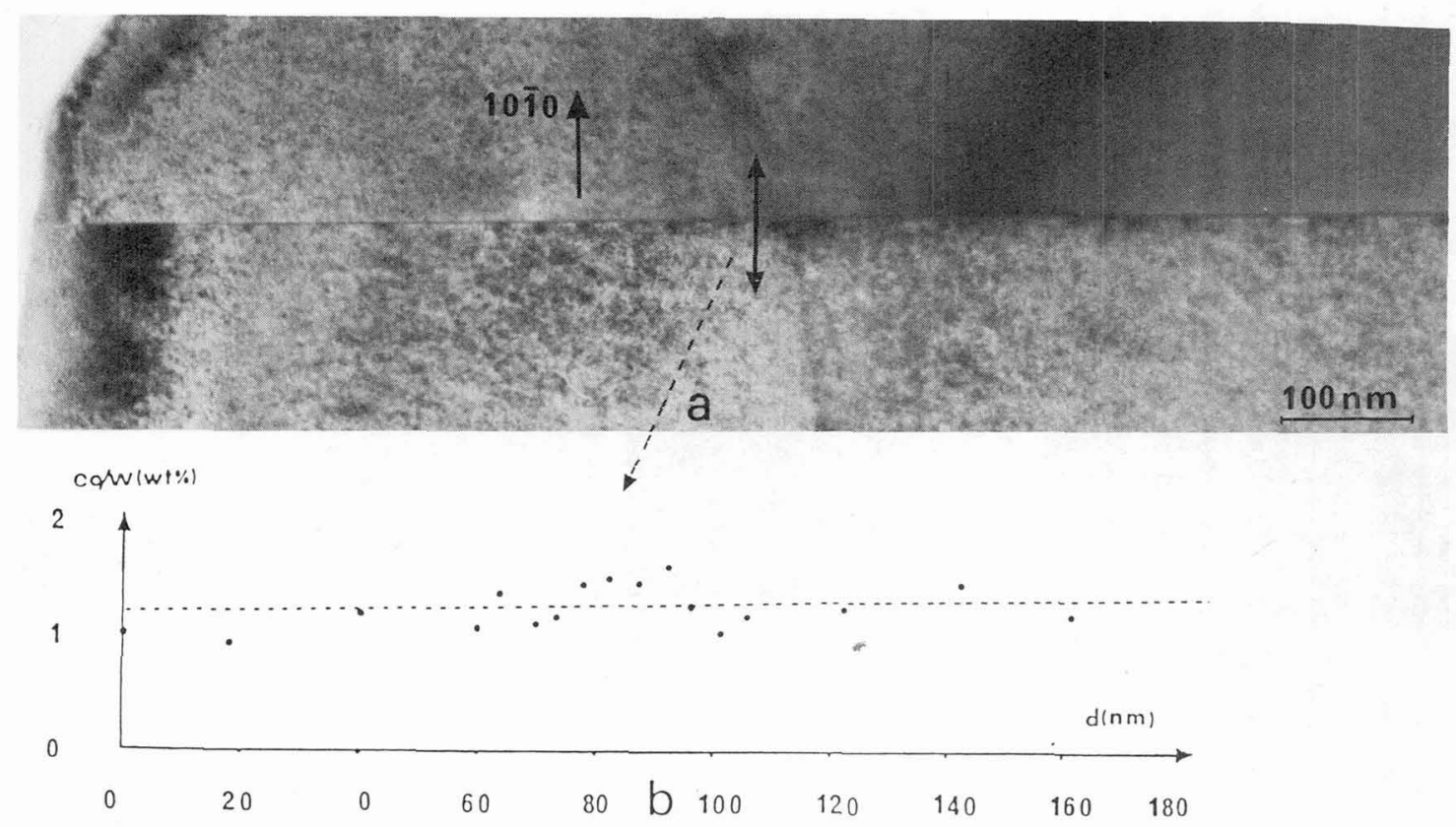

Fig. 5 : $\Sigma 5$ (a) and the corresponding cobalt concentration profile (b). 